\section{Research Medicine, University of Pennsylvania : Prof. Colin M. MacLeod}

Dr. Colin M. MacLeod, professor of microbiology and chairman of the Department of Microbiology at New York University College of Medicine since 1941, has been appointed John Herr Musser professor of research medicine and chairman of the Department of Research Medicine of the School of Medicine of the University of Pennsylvania. He succeeds Dr. William C. Stadie, who has been made emeritus professor. A Canadian by birth, Dr. MacLeod is a giaduate of MeGill University Medical School, and during 193441 he was a member of the staff of the Rockefeller Institute for Medical Research in New York. Dr. MacLeod's special fields of interest are infectious diseases, microbial genetics and immunology. He is a membei' of the Armed For'ces Fpidemiological Board and was president of that Board during 1947-55. He is a member of the Executive Committee of the Division of Medical Sciences of the National Research Council, and last year was a member of the Special Committee on Medical Research of the National Science Foundasion. Since 1945 he has been associate editor of the Journal of Immunology. Dr. MacLeod is a member of the U.S. National Academy if Sciences, the American Association of Immunologists (president 1951-52), the Harvey Society (president 1955-56), and the Society of American Bacteriologists, among others.

\section{Hurricane Research in the United States}

THE Woods Hole Oceanographic Institution, Massachusetts, supported by the United States Weather Bureau, the United States Navy and the Office of Naval Research, is to trace the hurricanes, which biing disaster to the eastern seaboard of the United States, to their birthplace over the ocean. They are formed in summer between about latitudes $5^{\circ}$ and $8^{\circ} \mathrm{N}$., and so far as is known at present they occur after a period of abnormally light winds across the northern half of the trade-wind belt. The Woods Hole scientisis suggest that these conditions lead to unusually high sea-surface temperatures and abnormally high humidity in the lowei layer of the atmosphere-probably because fewer sea-salt nuclei are carried up from the surface and less rain is initiated. When there is sufficient instability to produce winds to raise whitecaps, more nuclei will be carried up, and under extreme conditions the condensation, release of latent heat and increased convection will grow into a hurricane.

To make the basic observations and to test such ideas, a 125-ft. ex-coastguard cutter has been converted for research in marine meteorology. In addition to the usual meteorological and upper-air observations, detailed measurements will be made of the temperature and state of the sea surface. The work will be done in close collaboration with an air. borne team supplied by the U.S. Weather Bureau. A better understanding of the physical processes which produce the hurricanes will facilitate prediction, and there is a hint in the plans that it may be practicable to prevent the formation of a large organized disturbance by using rain-making techniques at scattered points before the conditions become critical. The new research ship Crawford carries eight scientific workers and a crew of fourteen. She carries supplies for a month, and fuel for 6,000 miles at 12 knots. She sailed from Woods Hole for the hurricane-generating region on July 3.

\section{Atoms in Industry}

P.E.P. (Political and Economic Planning) has recently issued two pamphlets entitled "Atoms in Industry", which provide an excellent appreciation of the British nuclear power plan and of the problems associated with its implementation. The first pam. phlet gives estimates drawn from recent publications of the probable cost of the electricity to be generated in tho early gas-cooled, graphite-moderated stations ; deals with the increased importance relative to coalfired stations of capital costs and the likely impact of the operation of sources of nuclear power on the national economy; and outlines the organization of the United Kingdom Atomic Energy Authority and its present and possible future relationship to manufacturing industry. The second discusses the factors governing the location of nuclear-power stations and the safety and insurance of these stations; and summarizes the steps which are being taken to establish effective international co-operation. It also incorporates a section dealing with radioactive isotopes, the techniques and economics of their application in industry, and the arrangements which the Atomic Energy Authority has made for their exploitation. It is stated in the conclusion that the account has been written strictly in the context of the present state of commercial developments, so that no attempt has been made to outline and compare the more advanced forms of power reactor which may emerge as alternatives to the gascooled, graphite-moderated type within the next decade, or to consider the prospects of nuclear propulsion.

The pamphlets will be found useful both by those directly concerned and those to whom developments in the peaceful utilization of nuclear energy are only of general interest. They would have been even more valuable to both classes of reader, however, had attention been given to the extent to which these developments may be hampered by the present shortage in Britain of scientists, technologists and technicians, as was made very clear in an article in Nature of December 24, 1955.

\section{Technical Education and Industry}

THe Federation of British Industries has issued a memorandum welcoming the White Paper on Technical Education but is reserving overall appraisal until the universities have published their plans for technological education for the quinquennium 1957 62 , pointing out that account must also be taken of the 'bulge' in population which now has its peak among those entering the secondary schools. In the view of the Federation, the plans are not specific enough. No attempt has been made to specify the time within which the proposed increases in the numbers of technicians and technologists is to be achieved, nor is it indicated how the Government proposes to secure the essential co-operation from the public, parents, teachers and industry. While suggesting curtailment of the development of new colleges of advanced technology in the London area, the Federation appears to accept the Government's target figure and merely queries the distribution. It emphasizes the value of co-operation between industry and technical colleges at the level of the governing bodies, but stresses also the value of advisory committees of industrial specialists and teachers. The White Paper is regarded as too complacent in regard to the recruitment and training of 